\title{
RFID Based Attendance System
}

\author{
Ajay Joshi ${ }^{1}$ | Aman Ahmad $^{2}$ | Arpit Saxena ${ }^{3}$ | Poonam Juneja \\ ${ }^{1}$ Department of Electrical and Electronics Engineering, Maharaja Agrasen Institute of Technology. \\ ${ }^{2}$ Department of Electrical and Electronics Engineering, Maharaja Agrasen Institute of Technology. \\ ${ }^{3}$ Department of Electrical and Electronics Engineering, Maharaja Agrasen Institute of Technology. \\ ${ }^{4}$ Department of Electrical and Electronics Engineering, Maharaja Agrasen Institute of Technology.
}

\section{To Cite this Article}

Ajay Joshi, Aman Ahmad, Arpit Saxena and Poonam Juneja, "RFID Based Attendance System", International Journal for Modern Trends in Science and Technology, Vol. 07, Issue 01, January 2021, pp.-40-43.

\section{Article Info}

Received on 22-November-2020, Revised on 18-December-2020, Accepted on 22-December-2020, Published on 28-December-2020.

\section{ABSTRACT}

RFID is an acronym for "radio-frequency identification" RFID technology is an automatic wireless identification system that works by the help of two components: a card and a reader. Using the RFID technology, the conventional system of taking attendance can be completely transformed to be more in line with strides in digitalization. This system will help the authorities manage the attendance system in a more methodical, efficient and time saving manner. The proposed system has been implemented through a prototype that has proved the effectiveness of the concept in easing the logistics of taking attendance as a result of the automation due to the use of the RFID technology. The design of the system is simple, cost effective and agile making it a good candidate for commercial and academic purposes.

KEYWORDS:RFID; Reader and Tags/Cards.

\section{INTRODUCTION}

The Radio Frequency Identification (RFID) technology is gaining momentum nowadays with its applications being seen in various fields such as industries, offices, transportation, agriculture, etc. The conventional method of manual attendance in educational institutions is often cumbersome and time consuming. However, this problem can be mitigated using the RFID technology. Radio Frequency Identification, is an automatic identification technology used for retrieving from or storing data on to RFID Tags without making any physical contact [1]. The RFID system comprises an RFID reader, tags, a backend storage system and also an intermittent part that contains all the electrical elements. This RFID based attendance system has a storage that stores the unique identification number of the student/employee with the attendance system being user friendly for commercial purposes. The principal objective is to make a system that will take the attendance of authorized individuals, record the data along with time and date and store in an internal SD card file, and finally store the data inside the EEPROM. Both hardware and software parts have been synchronized in order to serve the aforementioned objective. The RFID hardware has been relied upon to take the attendance of users. Each user would be provided with an individual RFID tag and its record will be maintained.
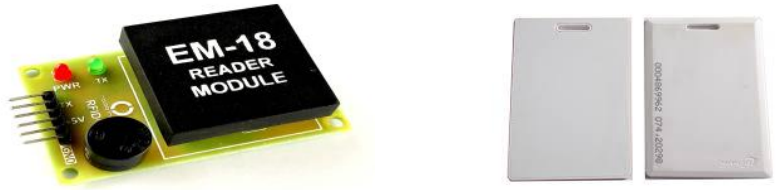

Fig. 1. RFID Reader and cards 


\section{LITERATURE REVIEW}

In 2013, Zhang Yuru, Chen Delong and Tan Liping illustrated a system in which hardware nodes based on RFID technology have been proposed. The designed system significantly improves the productivity and reduces wastage of human and material resources.[2]

The immense potential of RFID based systems has been identified and explained in literature earlier.It will open the door to applications which were unthought of a few years ago. Also the evolution of the technology and role of individual components has been explained in detail.[3]

The use of object counters in RFID based systems has also been shown. Such a system significantly improves the current manual process of taking attendance in the University Environment. It also promotes a fully automated approach in monitoring the students in the Campus.[4]

The application of GSM has also been studied to send SMS to a guardian when a student enters the campus.[5]

\section{METHODOLOGY}

A. Hardware Components:

The hardware components of this project include:

1) RFID Reader: A radio frequency identification reader (RFID reader) is a device used to extract information from an RFID tag, which is used to track individual objects. Radio waves are used to transfer data from the tag to a reader. Reader does not require line of sight communication with tags. It means that Reader detects the RFID tag even if there is some object between Card and Reader.

2) RFID tags: An RFID tag consists of two parts - an antenna for transmitting and receiving signals, and an RFID chip (or integrated circuit, IC) which stores the tag's ID and other information. RFID tags are affixed to items in order to track them using an RFID reader and antenna.

3) Arduino UNO: It is a microcontroller board based on 8-bit ATmega328P. In addition to ATmega328P, it also contains other components like serial communication, crystal oscillator, voltage regulator, etc. It has 14 digital and 6 analog pins. A USB connection and a reset switch is also present on the board. It also has a $1 \mathrm{~kb}$ EEPROM which stores the data.
4) DS 3231 RTC MODULE: RTC means Real Time Clock. RTC modules are simply TIME and DATE remembering systems which have battery setup.

5) Liquid Crystal Display: It is used to show current time and various messages. These messages are Invalid card, valid card, attendance of student. We have used $20 * 4$ alphanumeric displays.

\section{B. Software Requirements:}

The software used are as follows:

1. Arduino IDE: The Arduino Integrated Development Environment (IDE) is a cross-platform application (for Windows, mac OS, Linux) that is written in the programming language Java. We use this to write and upload the code for the RFID components.

2. Proteus Design Suite: The Proteus Design Suite is a software tool suite used primarily for electronic design automation.

This software was used for simulating the circuit.

\section{Interfacing RFID Reader to Arduino}

We made connections as shown. We connected the Ground Pin of RFID reader to the ground pin of the Arduino. We used the SoftwareSerial Library of arduino which enables digital pins to be used in serial communication.We have used Pin 9 as the $\mathrm{Rx}$ of Arduino.(Hardware Rx pin or Pin 0 of arduino can also be used).

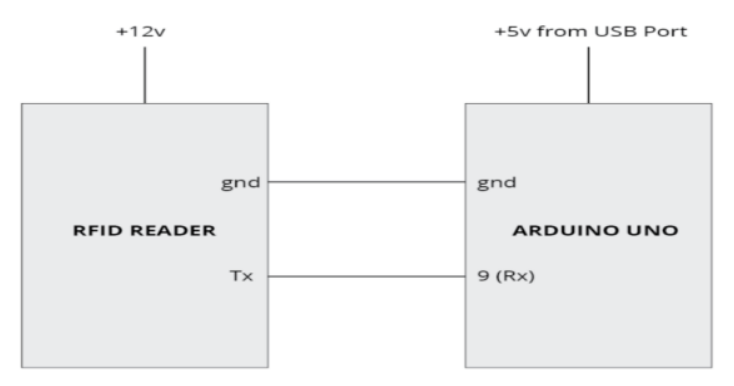

Fig 2. Interfacing with arduino 
Fig 3. Program for Interfacing RFID reader with arduino

D. Interfacing $20 \times 4$ LCD Display with Arduino

The LCD we are using has 16 pins. We connected the pins according to the schematic. Then we checked if the lcd works by powering up the arduino. The built in library "LiquidCrystal.h" has been used here.
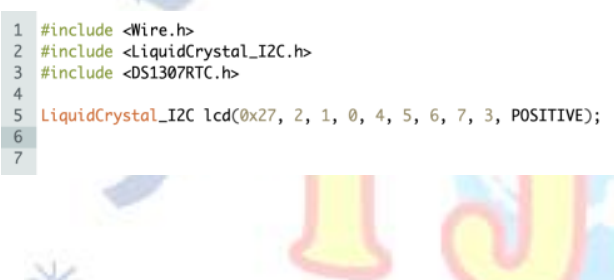

Fig 4. Code for interfacing the LCD display

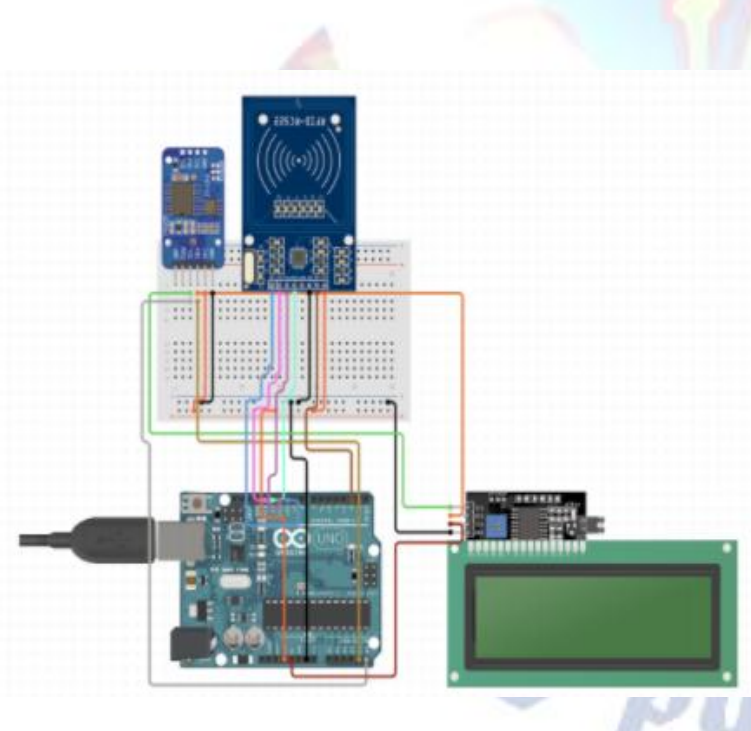

Fig 5 : Schematic diagram of circuit

\section{PRINCIPLE OF OPERATION}

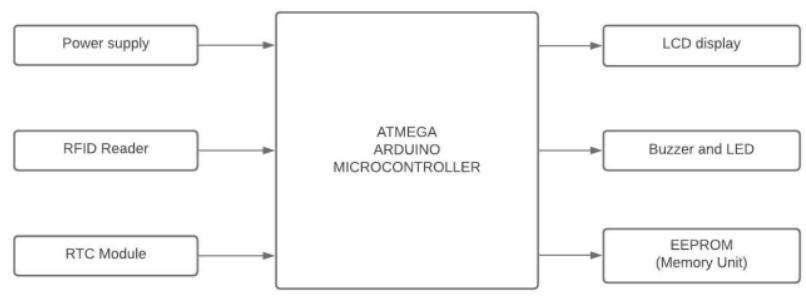

First off, The RFID is interfaced with the Arduino as shown.

In real time, RFID tags can be issued to the students with their roll numbers on them. RFID reader has copper winding in it which acts as an antenna. When the tag is brought near it, data is transferred to the reader due to the mutual inductance energy. The data is then transferred to the microcontroller which checks for it continuously. The data is then stored in a database. The microcontroller takes the attendance only if the tag is authenticated.

As shown in the circuit diagram, the transmit and receive pins of the RFID reader are connected to the corresponding transmit and receive pins of the microcontroller. The arduino receives data from the reader module through this channel. The system uses a $20 \times 4$ LCD module for displaying purposes and an RTC module is also connected which stores the time readings. The RTC Module is connected to the Arduino via the SCL and SDA pins using I2C protocol.

\section{IV.RESULTS}

The Project "RFID based attendance System" has been completed and final Testing is completed. In the testing mode, we used the following data:

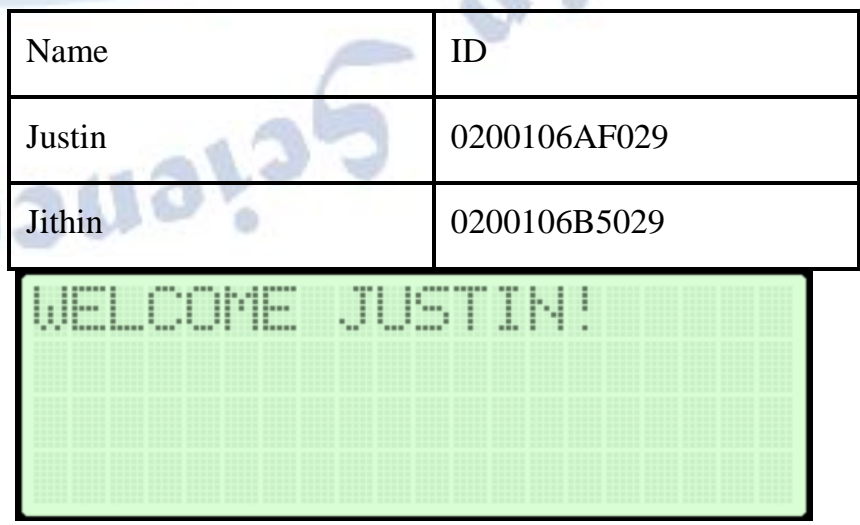

Fig.7 LCD snapshot while attendance is being registered 


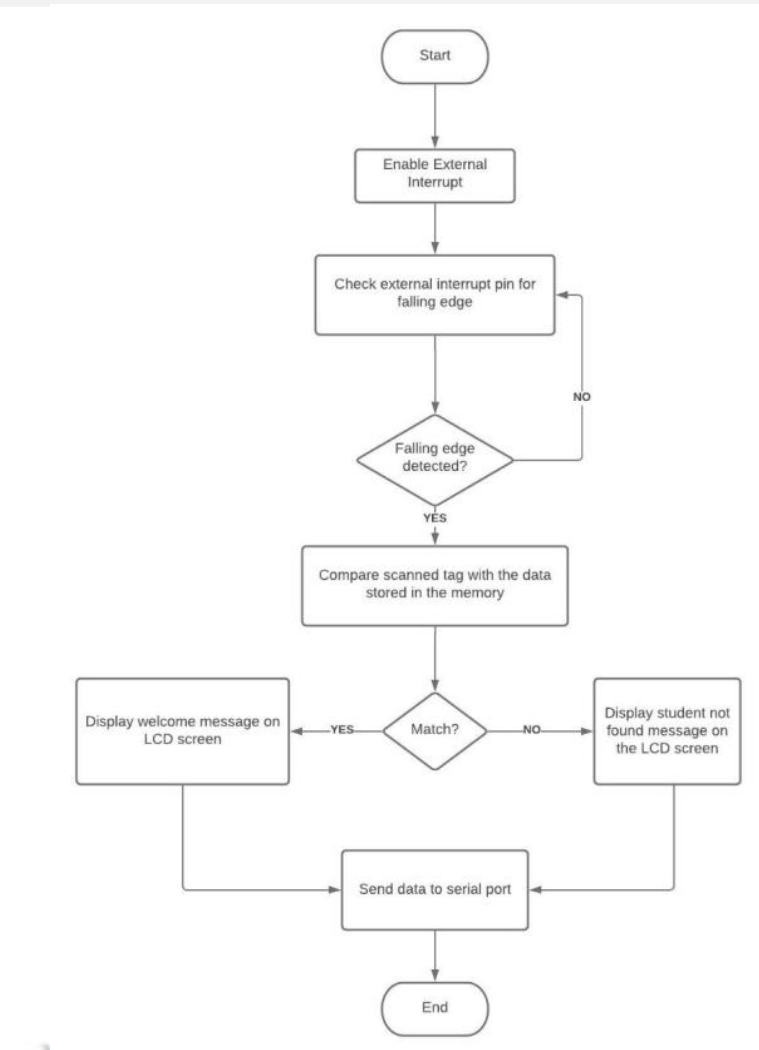

Fig.8 Flowchart of the Operation

\section{v. CONCLUSION}

The successful design and implementation of an automated attendance system based on RFID technology has been successfully presented through the means of this paper. The system developed provides an accurate, simple and cost effective means to register the attendance in educational institutions and effectively shifts the paradigm towards a digital and contactless environment.

Moreover, owing to the compactness and the portability of the system, it makes it all the more conducive to be deployed as and when required.

\section{FUTURE WORK}

RFID technology is budding and expanding as the world progressively moves towards a contactless environment. More so because unlike barcode scanners, RFID is bereft of the line of sight paradigm i.e. the tag doesn't need to be pointed directly over the reader. Instead, the user can get a scan even from feet away from the reader. Further, in addition to being cost effective, RFID alleviates the scope of malpractices and errors. Another point to note here is that this system can further be strengthened by introducing components like a fingerprint scanner if the need arises. Also the scope of this RFID based system can be extended to a range of operations like library management, parking security management, etc.

\section{REFERENCES}

[1] Lim,T.S., Sim,S.C. \&Mansor,M.M.(October 4-6, 2009), -RFID Based Attendance System\| 2009 IEEE Symposium on Industrial Electronics and Applications (ISIEA 2009), Kuala Lumpur, Malaysia.

[2] Yuru,Z., Delong,C. \&Liping,T.(April, 2013), -The Research and Application of College Student Attendance System based on RFID Technologyll International Journal of Control and Automation Vol. 6, No. 2.

[3] Nainan,S., Parekh,R. \&.Shah,T. (October 4-6, 2009),--RFID Technology Based Attendance Management System\| IJCSI International Journal Of Computer Science Issues, Vol. 10, Issue 1 , No 1 .

[4] Agrawal,A.\&Bansal,A.(2013),-Online_Attendance Management System Using RFID with Object Counterl International Journal of Information and Computation Technology, ISSN 0974-2239 Volume 3, (c) International Research Publications House, Number 3 , pp. 131-138.

[5] Shukla,A.K. (2017), -Microcontroller Based Attendance System Using RFID and GSM|| International Journal of Emerging Technologies in Engineering Research(IJETER), Vol. 5, Issue 8

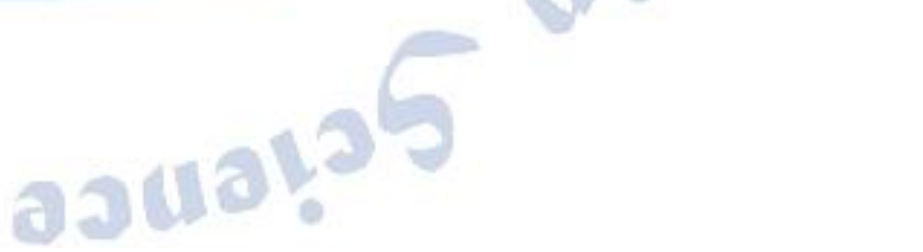

